\title{
Patent ductus arteriosus in preterm infants; experience of a tertiary referral neonatal intensive care unit: prevalence, complications, and management
}

\author{
Reem M. Soliman ${ }^{1}$, Fatma Alzahraah Mostafa ${ }^{1}$, Antoine Abdelmassih², Elham Sultan² and Dalia Mosallam ${ }^{\text {* }}$ (D)
}

\begin{abstract}
Background: Patent ductus arteriosus poses diagnostic and therapeutic dilemma for clinicians, diagnosis of persistent PDA, and determination of its clinical and hemodynamic significance are challenging. The aim of this study is to determine the prevalence of PDA in preterm infants admitted to our NICU, to report cardiac and respiratory complications of PDA, and to study the management strategies and their subsequent outcomes.

Result: Echocardiography was done for 152 preterm babies admitted to neonatal intensive care unit (NICU) on day 3 of life. Eighty-seven (57.2\%) preterms had PDA; 54 (62.1\%) non-hemodynamically significant PDA (non-hsPDA), and 33 (37.9\%) hemodynamically significant PDA. Hemodynamically significant PDA received medical treatment (paracetamol $15 \mathrm{mg} / \mathrm{kg} / 6 \mathrm{~h} \mathrm{IV}$ for 3 days). Follow-up echocadiography was done on day 7 of life. Four babies died before echo was done on day 7. Twenty babies (68.9\%) achieved closure after 1st paracetamol course. Nine babies received 2nd course paracetamol. Follow-up echo done on day 11 of life showed 4 (13.7\%) babies achieved successful medical closure after 2nd paracetamol course; 5 babies failed closure and were assigned for surgical ligation. The group of non-hsPDA showed spontaneous closure after conservative treatment. Pulmonary hemorrhage was significantly higher in hsPDA group. Mortality was higher in hsPDA group than non-hsPDA group. Conclusion: Echocardiographic evaluation should be done for all preterms suspected clinically of having PDA. We should not expose vulnerable population of preterm infants to medication with known side effects unnecessarily; we should limit medical closure of PDA to hsPDA. Paracetamol offers several important therapeutic advantages options being well tolerated and having more favorable side effects profile.
\end{abstract}

Keywords: Preterm, Echocardiograph, Patent Ductus Arteriosus, Paracetamol

\section{Background}

Patent ductus arteriosus (PDA) is a vital structure in fetal life where the systemic and pulmonary circulations function in parallel and thus, cardiovascular function is dependent on the presence of shunts. However, after birth and transition to postnatal circulation, where the systemic and pulmonary circulations are in series, the

\footnotetext{
* Correspondence: daliamosalam@hotmail.com

'Department of Pediatrics and Neonatal services, Faculty of Medicine, Cairo University hospital, Cairo, Egypt

Full list of author information is available at the end of the article
}

presence of shunts between the two circulations is nonphysiological and, if sustained and significant, may lead to hemodynamic compromise. Indeed, the ductus arteriosus closes in the vast majority of term infants within the first $48 \mathrm{~h}$ after delivery. However, in about $50-70 \%$ of the extremely low birth weight infants, the ductus arteriosus remains patent [1]. In the extreme premature population born at 24 weeks of gestation, only $13 \%$ of infants are found to have their ductus closed by the end of the first week [2].

\section{Springer Open}

(-) The Author(s). 2020 Open Access This article is licensed under a Creative Commons Attribution 4.0 International License which permits use, sharing, adaptation, distribution and reproduction in any medium or format, as long as you give appropriate credit to the original author(s) and the source, provide a link to the Creative Commons licence, and indicate if changes were made. The images or other third party material in this article are included in the article's Creative Commons licence, unless indicated otherwise in a credit line to the material. If material is not included in the article's Creative Commons licence and your intended use is not permitted by statutory regulation or exceeds the permitted use, you will need to obtain permission directly from the copyright holder. To view a copy of this licence, visit http://creativecommons.org/licenses/by/4.0/. 
Hemodynamic and respiratory consequences of PDA is related to the magnitude of left right shunt volume through PDA which leads to pulmonary congestion and respiratory function deterioration. This duct steal phenomenon causes a reduction in cardiac output which may lead to vital organs perfusion impairment, such as brain, kidney, and bowel [1].

This makes PDA an important issue from the clinical management perspective in the first few days of life in preterm infants [3]. Management of PDA is one of the most controversial topics in neonatal medicine. Hemodynamically significant PDA (hsPDA) in preterms may be associated with prolonged need for assisted ventilation, pulmonary hemorrhage, bronchopulmonary dysplasia (BDP), necrotizing enterocolitis (NEC), impaired renal functions, intraventricular hemorrhage (IVH), periventricular leukomalacia (PLV), and cerebral palsy [4].

The big dilemma about PDA management that still persists among neonatologists is who, when and what to treat with. Prophylactic therapy has gradually fallen out of favor and neonatal units have shifted towards a more conservative approach by treating only the clinically and echocardiographically significant PDA [5].

Prophylactic treatment involves the administration of indomethacin to all high-risk infants within the first $6 \mathrm{~h}$. Prophylactic indomethacin showed significant reductions in intraventricular hemorrhage, later symptomatic PDA and reduced PDA ligation rates but had little effect on other morbidities particularly respiratory outcomes [6].

Pre-symptomatic treatment involves using a variety of diagnostic methods, clinical and echocardiography, to detect ducts in the pre-symptomatic period and then treating medically at this time. The timing of the intervention is usually between $24 \mathrm{~h}$ and day 5 of life. There is significant reduction in later symptomatic PDA and reduction in duration of supplemental oxygen [7]. However, another opinion proposes that preterm PDAs should only be treated if there are clear signs of cardiac failure or compromise that can only be explained by the presence of a significant PDA [8]. Cyclooxygenase inhibitors, indomethacin, and ibuprofen are the most studied pharmacologic agents for the treatment of PDA [9]. Both drugs block prostaglandin synthesis, inducing ductal closure. Indomethacin will close the duct in most cases but at the expense of some side effects including: transient reduction of cerebral blood flow, oliguria, hyponatraemia, and gastro-intestinal complications. Most of these side effects are transient and self-limiting. Infusing the dose over 20 to $30 \mathrm{~min}$ may reduce but does not eliminate the effect on cerebral blood flow [10]. Oral ibuprofen is an alternative for the treatment of PDA. Oral ibuprofen was more effective than IV ibuprofen (84.6\%versus $62 \%$ ) for ductal closure in VLBW infants. Oral, but not IV, ibuprofen was associated with rise in
cystatin-C levels, a marker of impaired renal function, in preterm infants indicating that infants with borderline renal function may need careful monitoring [10].

The role of paracetamol (acetaminophen) as an alternative therapy for hsPDA closure has gained attention in recent years because of the potential adverse effects of COX inhibitors Moreover, paracetamol in oral form can be used successfully as the primary choice in PDA closure. Intravenous (IV) paracetamol could be an alternative treatment in patients in whom feeding was contraindicated or who had feeding intolerance. Paracetamol dose ranges from $10-15 \mathrm{mg} / \mathrm{kg} /$ dose every $6-8$ $\mathrm{h}$ for $72 \mathrm{~h}$ [11]. Paracetamol can be administered to infants with contraindications to cyclooxygenase inhibitors [12].

The aim of this study is to determine the prevalence of PDA in preterm infants admitted to our NICU; to report cardiac and respiratory complications of PDA and to study the management strategies and their subsequent outcomes.

\section{Methods}

This prospective interventional study was conducted in the Neonatal ICUs of Cairo University, over 6 months period from April 2018 to October 2018. Preterm neonate $\leq 34$ weeks gestation with patent ductus arteriosus were enrolled in our study. Exclusion criteria included babies suffering from perinatal asphyxia, complex congenital heart disease, lethal congenital anomalies, and/or chromosomal abnormalities. All the cases were subjected to history taking and clinical examination.

\section{Laboratory workup}

Complete blood picture, CRP, electrolytes, liver functions, kidney functions, capillary blood gases, and lactate level in blood were done for all included babies.

\section{Radiological imaging}

Chest X-ray was done to assess cardiac size and check for the presence of pulmonary edema, prominent main pulmonary artery or left atrial enlargement.

\section{Echocardiography}

Baseline echo was done to all preterm babies $\leq 34$ weeks admitted to NICU during study period on day 3 of life; with special emphasis on: PDA size, pulmonary artery pressure, and left atrium aortic ratio. Follow-up echo was done on days 7 and 11 of life.

PDA was considered hemodynamically significant if three or more of the following were present.:

\section{Clinical and radiological parameters}

Wide pulse pressure $>25 \mathrm{mmHg}$, hypotension: blood pressure below 3rd centile for gestational age, serum 
lactate $>4 \mathrm{mg} / \mathrm{dl}$, pulmonary edema, or cardiomegaly evident in chest radiograph.

\section{Echocardiographic parameters}

Ductal size $\geq 3 \mathrm{~mm}, \mathrm{LA} / \mathrm{AO}$ ratio $>1.5$. [13]

Bedside trans thoracic echo was done while the neonate was placed in the supine position without sedation. Ductal diameters were measured using two-dimensional and color flow at the pulmonary end, the median section, and the aortic end of the ductus on high left parasternal view. The size of the ductus was measured in $\mathrm{mm}$ at its narrowest part on a color Doppler image.

M-mode measurements of the left atrium/aortic root were assessed from parasternal views. IVRT (ms) by inserting PWD (pulse wave Doppler) between mitral and aortic valves [14].

\section{Analytic plan}

According to the results of echo done on day 3 of life; preterm babies $\leq 34$ weeks gestation included in the study were divided into two groups: PDA group (87 babies) and non-PDA group (65 preterms). PDA group were further subdivided into hemodynamically significant (33 babies), hemodynamically non-significant PDA (54 babies).

\section{PDA management}

All eligible preterms enrolled in the study were started in the delivery room on continuous positive airway pressure (CPAP) 6-8 cm H20 via a T piece device (Neopuff Infant T-piece Resuscitator, Fisher and Paykel Healthcare, Inc., Irvine, CA) using face mask if needed [15].

In NICU babies having non-hsPDA received conservative management in the form of respiratory support using bubble CPAP and pressure adjusted at 6-8 $\mathrm{cm}$ $\mathrm{H}_{2} \mathrm{O}$ and appropriately sized nasal masks. Fio2 levels were adjusted to maintain oxygen saturation levels within $90 \%$ to $95 \%$. Surfactant was administered whenever the fraction of inspired oxygen (Fio2) was greater than 0.3 or 0.4 for babies with a GA less than or greater than 28 weeks respectively. Non-invasive positive pressure ventilation was applied in infants with apnea or as an intermediate step before mechanical ventilation. Intravenous fluid therapy in the first week of life was closely monitored and restricted if needed. Parenteral nutrition was started from day one of life.

Babies with hsPDA received paracetamol $15 \mathrm{mg} / \mathrm{kg} /$ dose every $6 \mathrm{~h}$ for 3 days in addition to the conservative management. Babies were followed up until PDA closure or discharge whatever comes first. If failed duct closure after second course paracetamol, our cardiology team was consulted and baby was referred for device closure by catheterization or surgical ligation.

\section{Statistical analysis}

The collected data was revised, coded, tabulated and introduced to a PC using Statistical package for Social Science (IBM Corp. Released 2011. IBM SPSS Statistics for Windows, Version 20.0. Armonk, NY: IBM Corp.). Data were presented and suitable analysis was done according to the type of data obtained for each parameter. Data was summarized using mean, standard deviation, median, minimum, and maximum in quantitative data and using frequency (count) and relative frequency (percentage) for categorical data.

\section{Results}

One hundred and fifty-two preterm infants were enrolled in the study; $87(57.2 \%)$ babies had PDA. There were no statistically significant differences between PDA and non-PDA groups regarding gender, gestational age, birth weight mode of delivery, resuscitative measures, and maternal risk factors, apart from APH which was more frequent among mothers of PDA group. PDA group showed statistically significant higher frequency of poor APGAR scores $<5$ at 1 min when compared to non-PDA group $(P=0.04)$ (Table 1$)$.

PDA group have increased sepsis and pulmonary hemorrhage $(P=0.009,0.0016$ respectively). NEC, apnea, IVH, and BPD did not differ significantly between the two groups (Table 2).

Thirty-three preterms (38\%) had hsPDA, and 54 babies $(62.1 \%)$ had non-hsPDA. There were no statistically significant differences between the two groups regarding gender, gestational age, birth weight, mode of delivery, resuscitative measures, and maternal risk factors; apart from pregnancy-induced hypertension (PIH) which was more frequent among mothers of non-hsPDA group ( $P$ $=0.03)$. Mother receiving antenatal steroid were significantly higher in non-HSPDA group when compared to hsPDA group $(P=0.03)$ (Table 3$)$.

Figure 1 represents the pulmonary hypertension frequency in the studied population documented by echocardiography on third day of life.

Preterm babies having hsPDA had more RDS, pneumonia and pneumothorax evidenced by $\mathrm{X}$-ray findings compared to non-hsPDA group $(P=0.007)$.

The need for CPAP support $(38.9 \%$ vs $12.1 \%, P=$ $0.007)$, mechanical ventilation $(87.9 \%$ vs $57.4 \%, P=$ 0.003 ), and duration of mechanical ventilation (4 vs 9 days, $P=0.001$ ) were higher in hsPDA compared to non-hsPDA.

Pulmonary hemorrhage was associated with hsPDA when compared to non-hsPDA $(P=0.03)$. Sepsis, NEC, apnea, IVH and BPD did not differ between the two groups (Table 4).

Echocardiography was done on day 3 of life; 33 babies (38\%) were considered to have hsPDA according to our 
Table 1 Demographic and resuscitative data of the studied population

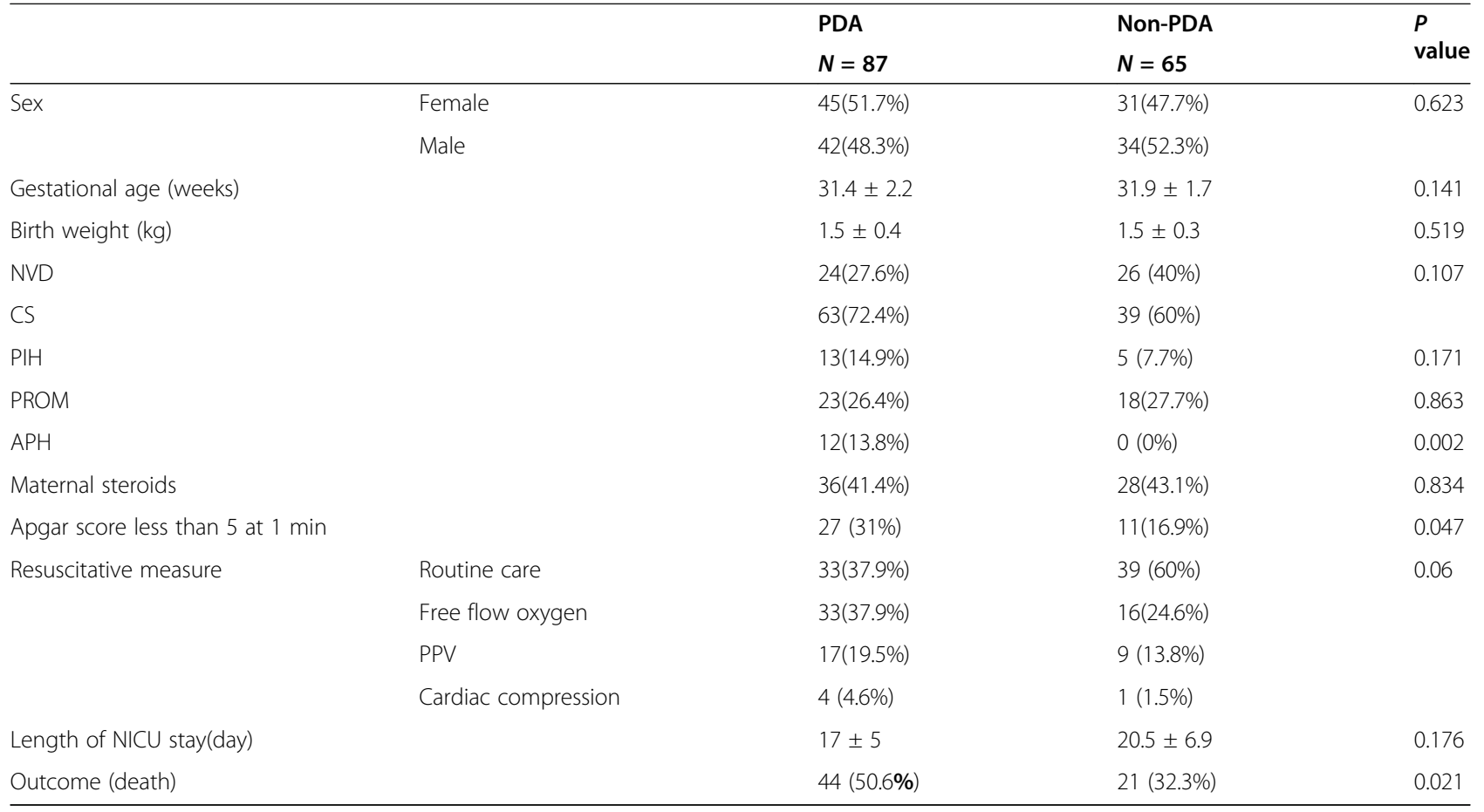

$p$ value is considered significant if $<0.05$

Abbreviations: NVD Normal vaginal delivery, CS Cesarean section, PIH Pregnancy-induced hypertension, PROM Premature rupture of membrane, APH Anti-partum hemorrhage

criteria, they received 3 days course of IV paracetamol $15 \mathrm{mg} / \mathrm{kg} / 6 \mathrm{~h}$. Four of them started paracetamol course but died before second echo assessment on day 7. One died because respiratory failure, two of them died because of septic shock and the other died because of pulmonary hemorrhage. Twenty-nine babies (87.9\%) did echo on day 7 of life to assess duct closure. Twenty (69\%) babies achieved PDA closure after completing first course paracetamol. Nine babies (31\%) received second course paracetamol, echo was done on day 11 of life, 4 babies (44.5\%) achieved PDA closure after 2nd course paracetamol, and 5(55.5\%) babies failed PDA closure after receiving two courses paracetamol. Our cardiology

Table 2 Comorbidities of the studied population

\begin{tabular}{llll}
\hline & $\begin{array}{l}\text { PDA } \\
\mathbf{N = \mathbf { 8 7 }}\end{array}$ & $\begin{array}{l}\text { Non-PDA } \\
\mathbf{N = 5 4}\end{array}$ & $\boldsymbol{P}$ value \\
\hline Sepsis & $80(92 \%)$ & $50(76.9 \%)$ & $0.009^{*}$ \\
NEC & $17(19.5 \%)$ & $14(21.5 \%)$ & 0.762 \\
Apnea & $10(11.5 \%)$ & $12(18.5 \%)$ & 0.227 \\
Pulmonary hemorrhage & $23(26.4 \%)$ & $7(10.8 \%)$ & $0.016^{*}$ \\
IVH & $35(40.2 \%)$ & $17(26.2 \%)$ & 0.070 \\
BPD & $3(3.4 \%)$ & $3(4.6 \%)$ & 0.726 \\
\hline
\end{tabular}

${ }^{*} p$ value is considered significant $<0.05$

Abbreviations: NEC Necrotizing enterocolitis, IVH Intraventricular hemorrhage, $B P D$ Broncho-pulmonary dysplasia team was consulted and they were referred for duct closure by catheterization or surgical ligation (Table 5).

\section{Discussion}

PDA's prevalence is inversely proportional to the gestational age with the prevalence of $20 \%$ at 32 weeks gestational age and exceeding $90 \%$ at 26 weeks gestational age. Prematurity not only increases the likelihood of PDA but also decreases the likelihood of its closure [16].

Management of PDA range from a less aggressive approach of modest fluid restriction and "watchful waiting, " to pharmacologic and/or surgical intervention. Pharmacotherapy includes the cyclo oxygenase inhibitors; indomethacin or ibuprofen, these agents have side effects including renal failure, brain white matter injury, spontaneous intestinal perforation, necrotizing enterocolitis, and increased bleeding tendency secondary to reduced platelet function, all in the face of treatment failure rates as high as $40 \%$ in very premature infants [17].

Clinical trials did not provide clear evidence to support the practice of closing PDA to improve short-term and long-term outcomes of premature infants. Trials conducted to introduce pharmacological treatment of PDA demonstrated the efficacy of these medications in closing PDA, but did not impact major outcomes such as 
Table 3 Demographic and resuscitative data of PDA groups

\begin{tabular}{|c|c|c|c|c|}
\hline & & $\begin{array}{l}\text { HSPDA } \\
N=33\end{array}$ & $\begin{array}{l}\text { Non-HSPDA } \\
N=54\end{array}$ & $P$ value \\
\hline \multirow[t]{2}{*}{ Sex } & Female & $16(48.5 \%)$ & $29(64.4 \%)$ & 0.636 \\
\hline & Male & $17(51.5 \%)$ & $25(55.6 \%)$ & \\
\hline Gestational age (weeks) & & $31.1 \pm 2.2$ & $31.7 \pm 2.2$ & 0.203 \\
\hline Birth weight (kg) & & $1.4 \pm 0.3$ & $1.5 \pm 0.4$ & 0.235 \\
\hline NVD & & $10(30.3 \%)$ & $14(31.1 \%)$ & 0.658 \\
\hline CS & & 23(69.7\%) & 40(88.9\%) & \\
\hline $\mathrm{PIH}$ & & $2(6.1 \%)$ & $11(24.4 \%)$ & 0.039 \\
\hline PROM & & $9(27.3 \%)$ & $14(31.1 \%)$ & 0.890 \\
\hline $\mathrm{APH}$ & & $6(18.2 \%)$ & $6(13.3 \%)$ & 0.359 \\
\hline Maternal steroids & & $9(27.3 \%)$ & $27(60 \%)$ & 0.037 \\
\hline Poor Apgar score & & $11(33.3 \%)$ & $16(35.6 \%)$ & 0.717 \\
\hline \multirow[t]{4}{*}{ Resuscitative measure } & Routine & $10(30.3 \%)$ & $23(51.1 \%)$ & 0.487 \\
\hline & PPV & $6(18.2 \%)$ & $11(24.4 \%)$ & \\
\hline & Free flow oxygen & $16(48.5 \%)$ & $17(37.8 \%)$ & \\
\hline & PPV + Cardiac compression & $1(3 \%)$ & $3(6.7 \%)$ & \\
\hline length of NICU stay (days) & & $17.8 \pm 5.2$ & $18.1 \pm 5.4$ & 0.906 \\
\hline Outcome (death) & & $22(66.7 \%)$ & $22(42.6 \%)$ & 0.029 \\
\hline
\end{tabular}

$p$ value is considered significant $<0.05$

Abbreviations: NVD Normal vaginal delivery, CS Cesarean section, PIH Pregnancy-induced hypertension, PROM Premature rupture of membrane, $A P H$ Anti-partum hemorrhage

mortality, CLD, NEC, and neurodevelopmental outcome [1].

In spite of the findings that acetaminophen showed promising results in closing PDA, there have been concerns about its effect on brain development and function. Without long-term outcome studies, the use of acetaminophen is still investigational [18].

Similarly, surgical ligation has not been shown to improve mortality and the incidences of certain morbidities associated with the procedure including vocal cord paralysis, thoracotomy, chylothorax, pneumothorax, scoliosis, retinopathy of prematurity (ROP), and most importantly increased incidences of cognitive delay and neurosensory/neurodevelopmental impairment are not uncommon. These findings caused reluctance to expose premature infants to the possible risks associated with surgical ligation whereas the benefit of PDA closure is still considered theoretical. For these reasons, a recent clinical report from the American Academy of Pediatrics attested that early and routine PDA treatment does not improve long-term outcome and that the value of selective treatment remains uncertain [1].

Hemodynamically significant PDA (hsPDA) is observed in more than $30 \%$ of premature infants with gestational age of 32 weeks [5]. Early identification of preterm infants who will subsequently fail to achieve ductal closure allows early initiation of intervention and reduces treatment failure. The diagnosis of hemodynamically significant ductal patency requires echocardiographic assessment. However, the definition of hemodynamically significant patent ductus arteriosus remains controversial [19].

Sehgal and Meneham [14] considered PDA as hemodynamically significant according to the following echocardiographic criteria: PDA diameter $>3 \mathrm{~mm}$, LA: Ao $>1.5$, LVO:SVC $\geq 4$, PDA:LPA $\geq 1$, EDLPAv $>30$ $\mathrm{cm} / \mathrm{s}$, PDA $\operatorname{Vmax}<1.5 \mathrm{~m} / \mathrm{s}$.

Yoo et al. [20] defined hsPDA if PDA had a transductal diameter $\geq 1.4 \mathrm{~mm} / \mathrm{kg}$ with significant left to right shunt confirmed by echocardiography. Presence of clinical symptoms due to hsPDA was defined as at least one of the three following clinical symptoms: oliguria $\leq 1$ $\mathrm{mL} / \mathrm{kg} / \mathrm{h}$ in the preceding $8 \mathrm{~h}$ before ibuprofen treatment, hypotension caused by PDA requiring inotropics more than $10 \mu \mathrm{g} / \mathrm{kg} / \mathrm{min}$ or respiratory difficulty requiring invasive mechanical ventilation.

Schwarz et al. [21] defined hsPDA if there was a leftto-right shunt through PDA confirmed by echocardiography and at least 3 of the following 6 criteria were met: LA/Ao-ratio > 1.5, PDA diameter $\geq 1.5 \mathrm{~mm} / \mathrm{kg}$ bodyweight, need of respiratory support (mechanical Ventilation or continuous positive airway pressure with supplemental oxygen), reverse, or zero end diastolic flow in ACA (= RI_ACA $\geq 1$ ), LVPEP/LVET $<0.32$. 


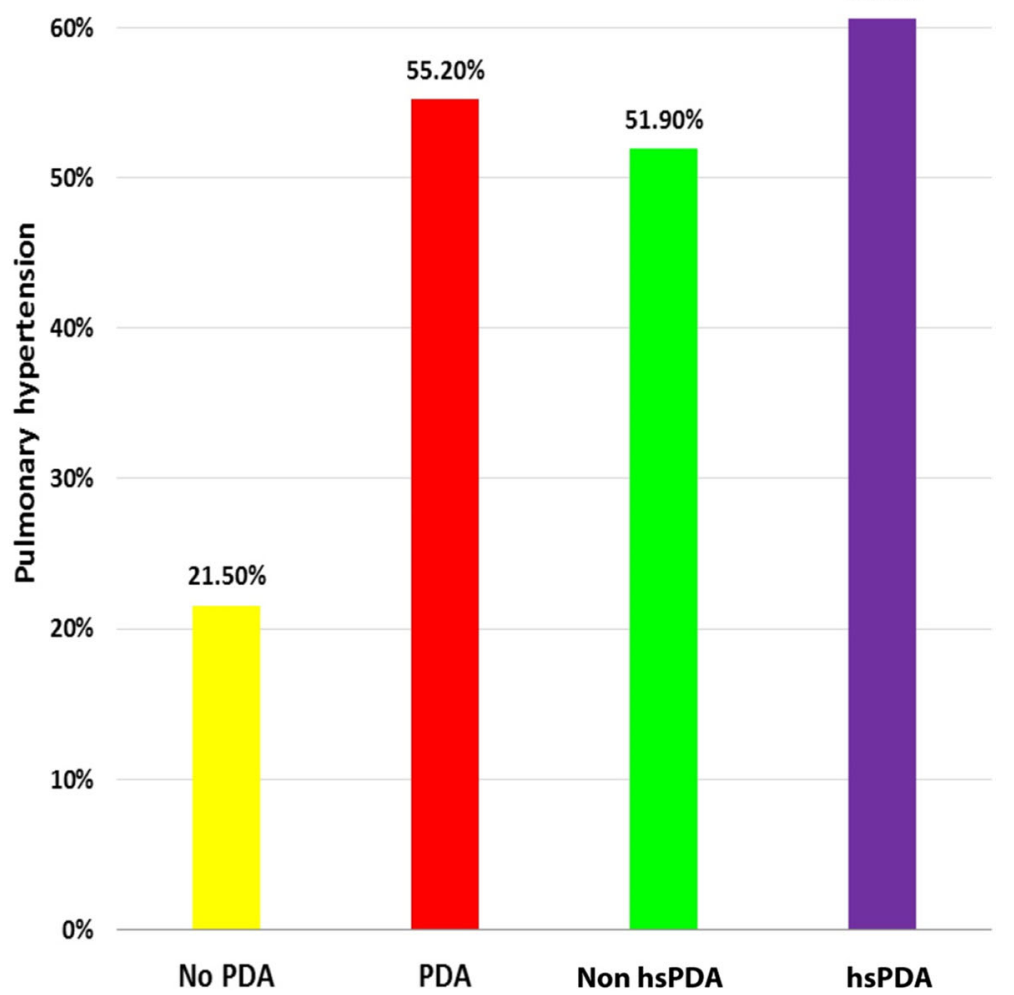

Fig. 1 Pulmonary hypertension frequency in studied population

The complications of hsPDA transcend heart failure to involving several organs leading to need for respiratory support, need for supplemental oxygen, prolonged mechanical ventilation, bronchopulmonary dysplasia, pulmonary hemorrhage, intraventricular hemorrhage, abnormal cerebral perfusion, necrotizing enterocolitis, and increased mortality [22].

Table 4 Comorbidities between HSPDA group and non HSPDA group

\begin{tabular}{llll}
\hline & $\begin{array}{l}\text { HSPDA } \\
\boldsymbol{N}=\mathbf{3 3}\end{array}$ & $\begin{array}{l}\text { Non-HSPDA } \\
\boldsymbol{N}=\mathbf{5 4}\end{array}$ & $\boldsymbol{P}$ value \\
\hline Sepsis & $32(97 \%)$ & $48(88.9 \%)$ & 0.245 \\
NEC & $6(18.2 \%)$ & $11(20.4 \%)$ & 0.803 \\
Apnea & $3(9.1 \%)$ & $7(13 \%)$ & 0.736 \\
Pulmonary hemorrhage & $13(39.4 \%)$ & $10(18.5 \%)$ & $0.032^{*}$ \\
IVH & $16(48.5 \%)$ & $19(35.2 \%)$ & 0.220 \\
BPD & $2(6.1 \%)$ & $1(1.9 \%)$ & 0.554 \\
\hline
\end{tabular}

${ }^{*} p$ value is considered significant $<0.05$

Abbreviations: NEC Necrotizing enterocolitis, IVH Intraventricular hemorrhage, $B P D$ Broncho-pulmonary dysplasia
Although none of the studies could prove a causeand-effect relationship between PDA and these morbidities, it is biologically plausible that a significant shunt across PDA causes fluctuation in cerebral blood flow contributing to the pathogenesis of IVH, persistently increased volume in pulmonary vascular bed leading to CLD, and steal from splanchnic circulation producing NEC [11].

One hundred fifty-two preterm babies $\leq 34$ weeks gestation admitted to NICU over 6 months period were included in the present study, 87 babies (57.2\%) had PDA, $33(37.9 \%)$ of them had hemodynamically significant PDA, while 54 (62.1\%) babies had hemodynamically non-significant PDA and 65 babies (42.8\%) did not have PDA.

Our results came in concordance with Danfang et al. [23] who studied 105 neonates $\leq 34$ weeks gestational age and found 34 (43.5\%) having hsPDA, 44 (56.5\%) having non-hsPDA and 27 (25.7\%) having no PDA.

Khositseth et al. [24] reported that prevalence of hsPDA among his preterm population babies was 29.3\%, non-hsPDA was $20.7 \%$, and $50 \%$ did not have PDA. 
Table 5 Medical treatment of HSPDA group

\begin{tabular}{llll}
\hline $\begin{array}{l}\text { HSPDA } \\
(\boldsymbol{N}=\mathbf{3 3})\end{array}$ & Success of closure & Failure of closure \\
\hline One course paracetamol & $29(87.9 \%)$ & $20(69 \%)$ & $9(31 \%)$ \\
Two course paracetamol & 9 & $4(44.5 \%)$ & $5(55.5 \%)$ \\
\hline
\end{tabular}

On the other hand, El-Saiedi et al. [25] found that prevalence of hemodynamically significant PDA among her study population was $52 \%$ which was higher than in our study (37.9\%). This may be explained by that the gestational age of included preterms was 32 weeks versus 34 weeks in the current study.

When we compared demographic data of PDA vs non-PDA group and hsPDA vs non-hsPDA we did not find any significant difference between the two groups, apart from APH which was higher among mothers of PDA group and PIH which was higher among hsPDA group $(P=0.002,0.039$ respectively).

Okur et al. [26] studied a total of 119 patients with gestational age $\leq 32$ weeks and birth weight $\leq 1500$ gms, his results contrasted with ours regarding birth weight which was lower in hsPDA but agreed with our results concerning length of NICU stay which did not differ significantly between the two groups.

In the current study, PDA group depicted poor Apgar scores (less than 5 at $1 \mathrm{~min}$ ) when compared to nonPDA group $(P=0.047)$. Okur et al $[26]$ and Lee et al [27] reported similar results.

The number of babies who needed CPAP or were mechanically ventilated and duration of mechanical ventilation were significantly higher in hsPDA when compared to non-hsPDA group $(P=0.007,0.003,0.001$, respectively). This came in agreement with Okur et al [26] who found that the duration of mechanical ventilation was longer in the hsPDA group when compared to non-hsPDA group.

Our study revealed more babies suffered metabolic acidosis and had high lactate level in PDA and hsPDA groups $(P=0.001,<0.001$, respectively). This came in contrast with El-Saiedi et al. [25] study which did not find difference in serum lactate level between hsPDA and non-hsPDA.

According to the present study, hemodynamic parameters: tachycardia, hypotension, wide pulse pressure measured on day 3 of life, were found significantly higher in the PDA and hsPDA group vs non-PDA and non-hsPDA $(P=0.009,0.005,0.001,0.038,0.001,0.001)$, respectively; these results coincided with those of Seghal and Menahem [14] who found that diastolic and mean blood pressure in his studied population were significantly lower whereas pulse pressure was significantly higher in hsPDA when compared to non-hsPDA and no PDA group $(P=0.005)$. On the other hand, Benitz et al.
[8] did not find any difference in the heart rate between hsPDA and non-HSPDA.

Lee JA et al. [27] stated that the core issue in management of PDA is to select patients who will benefit from the pharmacological and surgical ligation using epidemiological, clinical, and echocardiographic data, to avoid the unnecessary adverse consequences of such modalities. Controversy still remains regarding the benefit of treating PDA in preterm infants and studies are providing contradictory results.

Sehgal and Menahem [14] recommended that in practice PDA size on echocardiogram, chronic lung disease, and prolonged ventilation should be taken into consideration regarding the management of PDA.

In the current study, 29 preterm infants had hemodynamically significant PDA and received first course of paracetamol $15 \mathrm{mg} / \mathrm{kg} / 6 \mathrm{~h}$ for 3 days. Of them, $20(68.9 \%)$ cases closed, 9 babies failed closure and received 2nd course paracetamol. Four of them (13.7\%) closed, 5 babies (50\%) failed closure after 2nd course paracetamol and were assigned for device closure by catheterization or surgical ligation.

Our treatment strategy coincided with Pharandi et al [19]. Twenty babies whose gestational age $\geq 25$ weeks suffering from PDA were included in his study; 10 babies $(50 \%)$ closed after first course paracetamol; 10 babies failed closure and received second course paracetamol; of them, 4 closed and 6 failed closure after second course [28].

On the other hand, Bagheri et al. [29] treated 67 babies whose gestational age $<37$ weeks with paracetamol for duct closure; $82 \%$ of his studied population closed after first course. Second course was given to those who failed closure; of them, $50 \%$ closed. We attributed difference between our results and this is regarding PDA closure rate after 1st course paracetamol to the higher gestational age of his studied population which was $<37$ weeks gestation vs $\leq 34$ weeks of our population. Accordingly, some of his babies would have undergone spontaneous closure regardless of paracetamol administration [28].

Regarding comorbidities and complications reported in the current study, sepsis and pulmonary hemorrhage were significantly associated with PDA when compared to non-PDA group $(P=0.009,0.016,0.07)$, respectively. Pulmonary hemorrhage was significantly associated with HS PDA when compared to non-hsPDA $(P=0.031)$. 
This data came in agreement with Okur et al. [26] who reported no difference in early neonatal sepsis, IVH, BPD between hsPDA and non-hsPDA groups.

However, Lee et al. [27] found more infants suffering from early sepsis in the PDA group when compared with the non-PDA group. Visconti et al. [30] concluded that late sepsis was significantly coexisting with hsPDA. In his study, four infants had re-opening of ductus arteriosus and three other infants developed PDA in the course of late sepsis attacks which may be explained by the effects of cytokines released during sepsis.

We found that more babies died in PDA group when compared to non-PDA group and more babies suffering from hsPDA died compared to non-hsPDA; however, we do not attribute this to PDA nor can we prove a cause effect relationship.

This data comes in agreement with the studies of Okur et al. and Visconti et al. [26, 30] which revealed that hsPDA patients have higher mortality rate compared with non-hsPDA patient. On the other hand, Okur et al. [26] reported no significant difference between hsPDA group and non-hsPDA groups regarding mortality.

\section{Conclusion}

Management of patent ductus arteriosus in preterm infants is controversial topic. There are no generally accepted guidelines for diagnosis, management, or followup. Echocardiographic evaluation should be done for all preterm babies. The definition of hemodynamic significance varies because of the use of different echocardiographic criteria. The detailed risks and benefits of available treatment alternatives are still under investigation. An individualized therapeutic strategy with especial emphasis on identification of hemodynamically significance seems to be the way forward. There has been a general shift in the management of PDA in preterm neonates from the aggressive approach to a more conservative approach. Paracetamol offers several important therapeutic advantages over current treatment options being well tolerated and having more favorable side effect profile. Future prospective studies are needed to determine if conservative management of PDA without medical or surgical intervention is associated with increased mortality or chronic lung disease and which sector of preterm babies would benefit from PDA treatment. We should not expose vulnerable population of premature infants to medication with known side effects unnecessarily, we should limit medical closure of PDA to hsPDA.

\section{Abbreviations}

BPD: Bronchopulmonary dysplasia; BW: Birth weight; CPAP: Continuous positive airway pressure; CRP: C-reactive protein; CS: Caesarian section; DA: Ductus arteriosus; ECHO: Echocardiography; GA: Gestational age;
hsPDA: Hemodynamic significant patent ductus arteriosus; IVH: Intraventricular hemorrhage; IVRT: Isovolumic relaxation time; LA/ AO: Left atrium aortic ratio; LAX: Left axis; NEC: Necrotizing enterocolitis; NICU: Neonatal intensive care unit; NSAID: Non-steroidal anti-inflammatory drugs; PDA: Patent ductus arteriosus; PIH: Pregnancy-induced hypertension

\section{Acknowledgements}

I would also like to thank the whole members of the NICU Department, at Abuelrish Pediatric Hospital for their true support and help.

\section{Authors' contributions}

All authors reviewed the final version of the manuscript, believe it represents valid work, and approve it for publication. As an Author, I certify that none of the material in the Article has been published. All authors have read and approved the manuscript. Study conception and design: FA, RM.Data acquisition: ES, MA, DM, AA. Analysis and data interpretation: FA, RM, AA, ES. Drafting of the manuscript: DM, RM. Critical revision: FA, RM, DM. All authors read and approved the final manuscript.

\section{Funding}

The authors have no financial relationships relevant to this article to disclose.

\section{Availability of data and materials}

The corresponding author had full access to all of the data and takes full responsibility for the veracity of the data and statistical analysis.

\section{Ethics approval and consent to participate}

The trial was based on Master of Science thesis approved by Pediatric Department Committee for Post-Graduate Studies and Research, and by Post-Graduate Studies and Research administration, Faculty of Medicine, Cairo University, Egypt. The reference number is not applicable as this was applied 5 months ago while our research was done before that. Thesis was approved in 20 May 2018. Written consents were obtained from parents of study participants.

Investigations and all lines of treatments were clarified.

\section{Consent for publication}

Not applicable.

\section{Competing interests}

There is no financial nor non-financial competing interests.

\section{Author details}

${ }^{1}$ Department of Pediatrics and Neonatal services, Faculty of Medicine, Cairo University hospital, Cairo, Egypt. ${ }^{2}$ Faculty of Medicine, Cairo University, Cairo, Egypt.

Received: 4 January 2020 Accepted: 6 November 2020

Published online: 08 December 2020

\section{References}

1. Benitz WE (2016) Patent ductus arteriosus in preterm infants. Pediatrics 137(1):e20153730

2. Clyman Rl, Couto J, Murphy GM (2012) Patent Ductus Arteriosus: Are Current Neonatal Treatment Options Better or Worsen No Treatment at All? Semin Perinatol 36(2):123-129

3. Hamrick SE, Hansmann G (2010) Patent ductus arteriosus of the preterm infant. Pediatrics 125(5):1020-1030

4. Evans N (2003) Current controversies in the diagnosis and treatment of patent ductus arteriosus in preterm infants. Adv Neonatal Care 3:168-177

5. Mitra S, Rønnestad A, Holmstrøm H (2013) Management of Patent Ductus Arteriosus in Preterm Infants-Where Do We Stand? Congenit Heart Dis 8 : $500-512$

6. Zahn EM, Nevin P, Simmons C, Garg R (2015) A novel technique for transcatheter patent ductus arteriosus closure in extremely preterm infants using commercially available technology. Catheter Cardiovasc Interv 85:240

7. El-Khuffash AF, Jain A, McNamara PJ (2011) Enhancing the care of preterm infants undergoing surgical ligation of a patent ductus arteriosus. Congenit Cardiol Today 6:1-11

8. Benitz WE (2010) Treatment of persistent patent ductus arteriosus in preterm infants: time to accept the null hypothesis? J Perinatol 30(4):241 
9. Jones JL, Craven PD, Attia J, Thakkinstian A, Wright I (2011) Network metaanalysis of indomethacin versus ibuprofen versus placebo for PDA in preterm infants. Arch Dis Childhood 96(1)

10. Ohlsson A, Walia R, Shah SS (2015) Ibuprofen for the treatment of patent ductus arteriosus in preterm or low birth weight (or both) infants. Cochrane Database Syst Rev:CD003481

11. Laughon MM, Simmons MA, Bose CL (2004) Patency of the ductus arteriosus in the premature infant: is it pathologic? Should it be treated? Curr Opin Pediatr 16(2):146-151

12. Terrin G, Conte F, Scipione A et al (2014) Efficacy of paracetamol for the treatment of patent ductus arteriosus in preterm neonates. Ital J Pediatr 40(1):21

13. Zonnenberg I, de Waal K (2012) The definition of a haemodynamic significant duct in randomized controlled trials: a systematic literature review. Acta Paediatr 101(3):247-251

14. Sehgal A, Menahem S (2013) Interparametric correlation between echocardiographic markers in preterm infants with patent ductus arteriosus. Pediatr Cardio 34(5):1212-1217

15. Sweet DG, Carnielli V, Greisen G et al. European Association of Perinatal Medicine. European consensus guidelines on the management of neonatal respiratory distress syndrome in preterm infants. 2013 update. Neonatology. 2013;103(4) 347: f5980

16. Rolland A, Shankar-Aguilera DD, Zupan-Simunek V, Boileau P (2015) Natural evolution of patent ductus arteriosus in the extremely preterm infant. Arch Dis Childhood Fetal Neonatal Ed 100:F55-F58 13

17. Sinha B (2013) Controversies in management of patent ductus arteriou in the preterm infant. J Pulmon Resp Med S13:007

18. Ohlsson A, Shah PS (2015) Paracetamol (Acetaminophen) for patent ducts arteriosus in preterm or low-birth weight infants. Cochrane Database Sys Rev 3:CD010061

19. Pharande P, Watson H, Tan K, Sehgal A (2018) Oral paracetamol for patent ductus arteriosus rescue closure. Pediatr Cardiol. 39:183-190

20. Yoo H, Lee JA, Oh S, Jung YH, Sohn AJ, Shin SH, Choi CW, Kim E, Kim B (2017) Comparison of the mortality and in-hospital outcomes of preterm infants treated with ibuprofen for patent ductus arteriosus with or without clinical symptoms attributable to the patent ductus arteriosus at the time of ibuprofen treatment. J Korean Med Sci 32:115-123

21. Schwarz CE, Preusche A, Christian M, Poets L, Axel R (2018) Prospective observational study on assessing the hemodynamic relevance of patent ductus arteriosus with frequency domain near-infrared spectroscopy. BMC Pediatrics 18:66

22. Sellmer A, Bjerre JV, Schmidt MR et al (2013) Morbidity and mortality in preterm neonates with patent ductus arteriosus on day 3. Arch Dis Child Fetal Neonatal Ed 98(6):F505-F510

23. Danfang L, Yunfeng L, Xiaomei T (2015) Clinical features and cardiac hemodynamics of patent ductus arteriosus in premature infants.Chinese. J Pediatr 53(3):187-193

24. Khositseth A, Muangyod N, Nuntnarumit P (2013) Perfusion index as a diagnostic tool for patent ductus arteriosus in preterm infants. Neonatology 104(4):250-254

25. El-Saiedi S, AbdelMassih AF, Sedky Y, Malash A, Hussain N, Alfons M, Essam $R$ (2019) Development of tissue Doppler-derived predictors of hemodynamically significant patent ductus arteriosus and the ability to incorporate it in targeted neonatal echocardiography protocol. J Saudi Heart Assoc 31:69-74

26. Okur N, Tayman C, Büyüktiryaki M, Kadıoğlu Şimşek G, Ozer Bekmez B, Altuğ N (2019) Can lactate levels be used as a marker of patent ductus arteriosus in pretermbabies? J Clin Lab Anal 33:e22664

27. Lee JA, Kim MJ, Oh S, Choi BM (2015) Current status of therapeutic strategies for patent ductus arteriosus in very-low-birth-weight infants in Korea. J Korean Med Sci. 30:S59-S66

28. Terek D, Yalaz M, Ulger Z, Altun OK, Kultursay N (2014) Medical closure of patent ductus arteriosus does not reduce mortality and development of bronchopulmonary dysplasia in preterm infants. J Res Med Sci 19(11):1074-1079

29. Bagheri MM, Niknafs PF (2016) Comparison of oral acetaminophen versus ibuprofen in premature infants with patent ductus arteriosus. Iran J Pediatr 26(4):e3975
30. Visconti L F, Morhy SS, Deutsch AD, Penha Tavares GM, Mussi Wilberg TJ, Souza Rossi FD. 2013; Clinical and echocardiographic characteristics associated with the evolution of the ductus arteriosus in the neonate with birth weight lower than $1,500 \mathrm{~g}$.

\section{Publisher's Note}

Springer Nature remains neutral with regard to jurisdictional claims in published maps and institutional affiliations.

\section{Submit your manuscript to a SpringerOpen ${ }^{\circ}$ journal and benefit from:}

- Convenient online submission

- Rigorous peer review

- Open access: articles freely available online

- High visibility within the field

- Retaining the copyright to your article

Submit your next manuscript at $\boldsymbol{\nabla}$ springeropen.com 